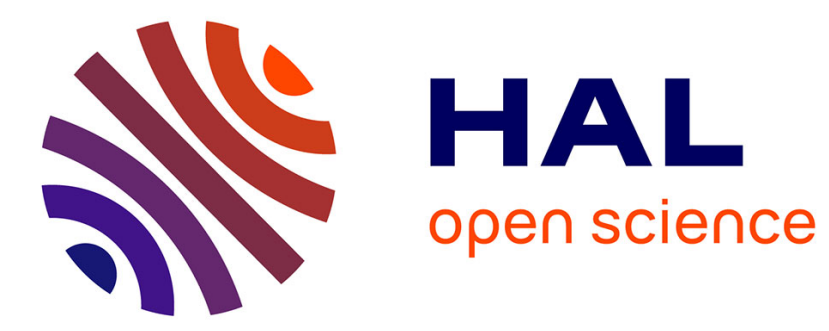

\title{
Gust loading factors with nonlinear pressure terms
}

Christian Soize

\section{To cite this version:}

Christian Soize. Gust loading factors with nonlinear pressure terms. Journal of Structural Division ASCE, 1978, 104 (6), pp.991-1007. hal-00770398

\section{HAL Id: hal-00770398 \\ https://hal.science/hal-00770398}

Submitted on 10 Apr 2013

HAL is a multi-disciplinary open access archive for the deposit and dissemination of scientific research documents, whether they are published or not. The documents may come from teaching and research institutions in France or abroad, or from public or private research centers.
L'archive ouverte pluridisciplinaire HAL, est destinée au dépôt et à la diffusion de documents scientifiques de niveau recherche, publiés ou non, émanant des établissements d'enseignement et de recherche français ou étrangers, des laboratoires publics ou privés. 


\title{
Gust Loading Factors with NonLinear Pressure Terms
}

\author{
By Christian Soize ${ }^{1}$
}

\section{INTRODUCTION}

A considerable number of theoretical and experimental studies have been carried out in the last $15 \mathrm{yr}$ with a view to providing an improved modeling of the wind structure near the ground and of the effects of wind on buildings. These studies include the development by A. G. Davenport $(6,7)$ of an analytical expression for the gust response factor of buildings in which the nonlinear pressure terms are neglected.

The purpose of this paper is to develop a similar expression in which these terms are taken into account. The main steps leading to this expression will be presented and numerical examples will be given showing the influence of the nonlinear terms on the magnitude of the response.

Problem Formulation and Analysis

The structure under consideration is assumed to be linearly elastic and to have $n$ degrees-of-freedom. Its vibrations are governed by the matrix equation:

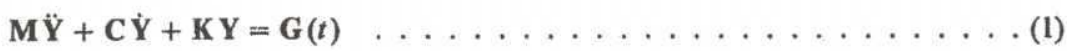

in which $\mathbf{M}, \mathbf{C}$ and $\mathbf{K}$ are real and symmetric $(n \times n)$ mass, damping and stiffness matrices, respectively, and $\mathbf{Y}$ and $\mathbf{G}$ are column $(n \times 1)$ matrices of the node displacements and of the external forces applied to the nodes, respectively.

The vibrations are examined in a plane parallel to the direction of the mean wind. Each node $i$ of the windward face may be approximatively assumed to carry a force $G_{i}(t)$ acting on its tributary area $S_{i}$; 


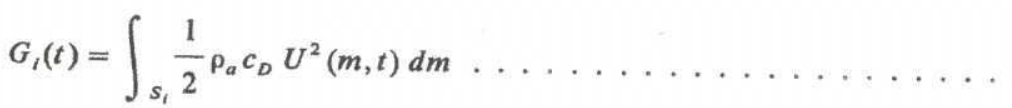

in which $c_{D}=$ the overall drag coefficient of the structure; $\rho_{a}=$ the air density; $m=$ a generic point at elevation $z ; U(m, t)=$ the longitudinal component of the wind velocity field in a point $\mathrm{m}$ and at the time $t ; S=U_{1} S_{t}$ with $S$ being the total area of the windward face, and where $d m=d y d z$. As noted, for example, in Ref. 32, virtual mass effects are negligible and have therefore not been included in Eq. 2. The longitudinal component of the wind velocity may be written as:

$U(m, t)=U(m)+V(m, t)$

in which $U(m)=$ the velocity averaged over $T$; and $V(m, t)=$ the longitudinal fluctuation modeled by a Gaussian stochastic field with zero mean and stationary in time. The $U(m)$ law $(1,5)$ is a function of site roughness and of a reference average wind $U_{R}$. For a given roughness and a fixed $U_{R}$, the stochastic field $V(m, t)$ is completely described and the expressions of its spectral density function as well as those of its coherence functions are known $(5,8,10,11,12,24)$.

Let $\sigma_{V}^{2}(m)$ denote the variance of $V(m, t)$. We denote:

$\left.\begin{array}{l}Z(m)=U^{2}(m)+\sigma_{V}^{2}(m) \\ Z(m, t)=V^{2}(m, t)+2 U(m) V(m, t)-\sigma_{V}^{2}(m)\end{array}\right\}$ $Z(m, t)$ is a stochastic field with zero mean and stationary in time. From Eqs.
3 and 4 there follows:

$\mathbf{G}(t)=\mathbf{G}(t)+\mathbf{F}(t)$

in which

$\left.\begin{array}{l}G_{i}(t)=\int_{s_{i}} \frac{1}{2} \rho_{a} c_{D} Z(m) d m \\ F_{i}(t)=\int_{s_{i}} \frac{1}{2} \rho_{a} c_{D} Z(m, t) d m\end{array}\right\}$

The solution of Eq. 1 may be written as $\mathbf{Y}=\mathbf{Y}+\mathbf{X}$ where $\mathbf{Y}$ is the average response solution of $\mathbf{K} \mathbf{Y}=\mathbf{G}$, which can be solved in a classic manner by a deterministic static analysis, and $\mathbf{X}$ is the column matrix $(n \times 1)$ of the displacement fluctuation solution of:

$\mathbf{M} \ddot{\mathbf{X}}+\mathbf{C} \ddot{\mathbf{X}}+\mathbf{K} \mathbf{X}=\mathbf{F}(t)$

In general, the matrix of structural damping is not numerically known and preference is given to the introduction of a critical damping rate for every vibration mode. The modal analysis gives a matrix solution:

$\mathbf{X}(t)=\int_{-\infty}^{t} \mathbf{H}\left(t-t^{\prime}\right) \mathbf{F}\left(t^{\prime}\right) d t^{\prime}$

in which $\mathbf{H}\left(t-t^{\prime}\right)=\Phi \mathbf{h}\left(t-t^{\prime}\right) \Phi^{T} ; \Phi=$ matrix of the vibration modes of the undamped system such that $\Phi^{T} \mathbf{M} \Phi=I ; \mathbf{h}(t)=$ diagonal matrix of 
the impulse responses $h_{i j}(t)=\delta_{j} h_{j}(t)$; and $\delta_{i j}=$ Kronecker symbol $h_{j}(t)=$ $e^{-\xi_{j} \omega_{j} t} / \omega_{j} \sqrt{1-\xi_{j}^{2}} \sin \left(\sqrt{1-\xi_{j}^{2}} \omega_{j} t\right)$, in which $\omega_{j}$ is such that $\left[\Phi^{T} \mathbf{K} \Phi\right]_{j j}=$ $\delta_{i j} \omega_{j}^{2}$ and $\xi_{j}<1$ the critical damping rate of the $j$ th vibration mode.

A scalar observation $D(t)$ in the structure can be a displacement, or a force, or a stress, etc. In view of the linear behavior of the structure, a column matrix $\mathbf{Q}$ of $(n \times 1)$ dimension exists such that: $D(t)=\mathbf{Q}^{T} \mathbf{Y}(t) . D(t)$ can be written as:

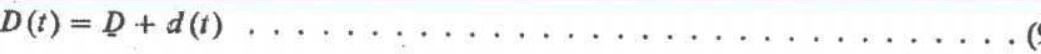

in which

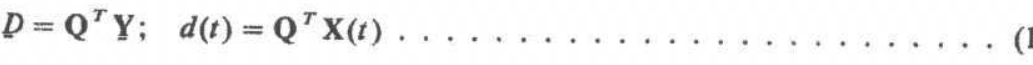

The fluctuation $d(t)$ can be written as:

$d(t)=\mathbf{Q}^{r} \int_{-\infty}^{t} \mathbf{H}\left(t-t^{\prime}\right) \mathbf{F}\left(t^{\prime}\right) d t^{\prime} \ldots \ldots \ldots \ldots \ldots \ldots$

The derivative $\dot{d}(t)$ of $d(t)$ at time $t$ can be written in Eq. 11 in substituting $\mathbf{H}$ by $\mathbf{H}$ such that $\dot{\mathbf{H}}(u)=d \mathbf{H}(u) / d u$.

The calculation of the mean of the extreme values over the time $T$ of $d(t)$ requires the joint probability density function $f_{2}(x, y)$ to be known at the time $t$ of the random variables $d_{t}$ and $\dot{d}_{t}$. Now the vectorial stochastic process $\mathbf{F}(t)$ is not Gaussian, because the transformation that allows to pass from $V(m, t)$ to $\mathbf{F}(t)$ is nonlinear. Therefore, $d(t)$ and $\dot{d}(t)$ are non-Gaussian stationary stochastic processes with zero mean. The random variables $d_{t}$ and $\dot{d}_{t}$ are not statistically independent (contrary to the Gaussian case). Nevertheless, the calculation of $f_{2}(x, y)$ can be made by calculating its Fourier transform.

Fourier Transform of $f_{2}$

The theoretical developments given in Ref. 26 permit the calculation, with no simplification of the Fourier transform $\hat{f}_{2}$ of $\hat{f}_{2}$. An analytical expression of $\hat{f}_{2}(u, v)$ is obtained in this manner. The joint probability density function $f_{2}$ of $d_{\text {, }}$ and $\dot{d}_{\text {, }}$ can therefore be calculated by simple inverse Fourier transformation. The analytical expression of $\hat{f}_{2}$ includes operators that are defined over functional spaces. For a numerical calculation of $\hat{f}_{2}$, it is necessary to project these operators on subspaces of finite dimensions (see Ref. 28).

From a numerical point of view, the value of $d(t)$ and $\dot{d}(t)$ at the time $t$ is not a function of the whole time history, because the dynamic behavior of the structure forms a filter. This results in the possibility of calculating $f_{2}$ at any fixed time $t$ and reducing the time integration interval $(-\infty, t)$ of Eq. 11 to a finite interval $\left(0, T_{1}\right)$. The joint probability density function $f_{2}$ that is sought then becomes the joint probability density function of the non-Gaussian and nonstatistically independent random variables $d_{T_{1}}=d\left(t=T_{1}\right)$ and $\dot{d}_{T_{1}}$ $=\dot{d}\left(t=T_{1}\right)$. The present study only gives the results that will be used for further developments in this paper. The results obtained are given in Appendix I. 


\section{Calculation of Peak Fluctuating Response}

Let $\xi$ be a level of $d(t)$. By taking into account the stationary state of $d(t)$, the mean of the number of upcrossing of the level $\xi$ by the trajectory of the $d(t)$ process in time $(0, T)$ can be written as follows (see Ref. 4):

$$
\mathscr{E}\left(N_{T}^{+}(\xi)\right)=T \int_{0}^{+\infty} y f_{2}(\xi, y) d y \ldots \ldots \ldots \ldots \ldots
$$

In calculating the gust loading factor " $g$," we proceed to the same type of analysis as that used by Davenport $(6,7)$ for the linear case. It is nevertheless assumed that in the nonlinear case, the distribution function $F_{\max }$ of the positive extreme values of $d(t)$ during the time $T$ is always written:

$F_{\max }(\xi)=\operatorname{Prob}(d \leq \xi)=\exp \left[-\mathscr{E}^{2}\left(N_{T}^{+}(\xi)\right)\right]$

which supposes that the threshold crossings at positive extreme values are independent events.

The mean of the positive extreme values over $T$ may then be written:

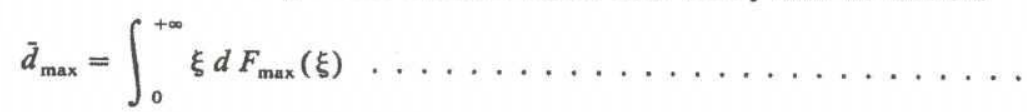

An analytical calculation of the Eq. 14 cannot be carried out by using Eqs. 42 and 13 , but a numerical calculation is quite possible. However, we want to obtain an analytical expression of " $\mathrm{g}$ " for the nonlinear case and to this end, the Edgeworth's series $(3,14)$ are used, which consist in developing $f_{2}$ in the form of a series comprising the normal law and its derivatives. In practice, for the wind loaded elastic structures we may stop the development at the 4th order. This makes it possible to find corrective factors of the gust factor by means of the linear theory.

Let $\alpha(\eta)$ be the normal probability density function with zero mean and unit variance. The derivatives of $\alpha(\eta)$ with regard to $\eta$ can now be written $d^{p} \alpha(\eta) / d \eta^{p}=(-1)^{p} H_{p}(\eta) \alpha(\eta)$, in which $H_{p}(\eta)$ are the Hermite polynomials (see Appendix II). The value $M_{p q}$ designates the moments of the random variables $d_{T_{1}}$ and $\dot{d}_{T_{1}}$ whose definition is given by:

$M_{p q}=\mathscr{E}\left(d_{T_{1}}^{p} \dot{d}_{T_{1}}^{q}\right)$

Because the two random variables $d_{T_{1}}$ and $\dot{d}_{T_{1}}$ have a zero mean, one has:

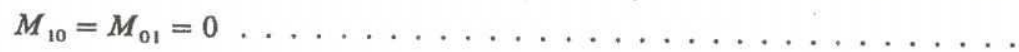

As a consequence, $M_{20}$ and $M_{02}$ are the variances of $d_{T_{1}}$ and $\dot{d}_{T_{1}}$, respectively. On the other hand, because the $d(t)$ process is stationary, $\mathscr{E}\left(d^{p}(t)\right)$ is a time independent constant; in differentiating with regard to the time, one obtains $\mathscr{E}\left(d^{p-1}(t) \dot{d}(t)\right)=0$, which leads for $p=1,2$ and 3 to:

$M_{11}=M_{21}=M_{31}=0$

Let $f_{R}(\eta, \zeta)$ be the joint probability density function of the normalized random variables $d_{R}=d_{T_{1}} \cdot M_{20}^{-1 / 2}$ and $\dot{d}_{R}=d_{T_{1}} \cdot M_{02}^{-1 / 2}$ :

$f_{R}(\eta, \zeta)=M_{20}^{1 / 2} M_{02}^{1 / 2} f_{2}\left(\eta M_{20}^{1 / 2}, \zeta M_{02}^{1 / 2}\right)$ 
The cumulants $k_{y}$ of the normalized variables $d_{R}$ and $\dot{d}_{R}$ are functions of the $M_{p q}$ moments. By taking into account Eqs. 16 and 17, it shown (28) that the cumulants until the 4 th order are such that:

$k_{10}=k_{01}=k_{11}=k_{21}=k_{31}=0$

$k_{30}=M_{30} M_{20}^{-3 / 2} ; \quad k_{12}=M_{12} M_{20}^{-1 / 2} M_{02} ; \quad k_{40}=M_{40} M_{20}^{-2}-3 ;$

$k_{22}=M_{22} M_{20}^{-1} M_{02}^{-1}-1 ; \quad k_{04}=M_{04} M_{02}^{-2}-3$

However, $k_{20}, k_{02}, k_{03}$, and $k_{13}$ are nonzero, their values need not be determined. The 4th order development of $f_{R}$ can now be written:

$f_{R}(\eta, \zeta)=\alpha(\eta) \alpha(\zeta)\left[1+\frac{k_{30}}{6} H_{3}(\eta)+\frac{k_{12}}{2} H_{1}(\eta) H_{2}(\zeta)+\frac{k_{03}}{6} H_{3}(\zeta)\right.$

$\left.+\frac{k_{40}}{24} H_{4}(\eta)+\frac{k_{13}}{6} H_{1}(\eta) H_{3}(\zeta)+\frac{k_{22}}{4} H_{2}(\eta) H_{2}(\zeta)+\frac{k_{04}}{24} H_{4}(\zeta)\right] \ldots$

By taking into account Eqs. 18 and 21, after having carried out all the calculations, it becomes possible to write Eq. 12 in the following form:

$\mathscr{E}\left(N_{T}^{+}(\xi)\right)=\lambda(x)\left(1+\sum_{j=0}^{4} a_{j} x^{j}\right)$.

in which

$x=\xi M_{20}^{-1 / 2}$.

$a_{0}=\frac{1}{24}\left(3 k_{40}-6 k_{22}-k_{04}\right) ; \quad a_{1}=\frac{1}{2}\left(k_{12}-k_{30}\right) ; \quad a_{2}=\frac{1}{4}\left(k_{22}-k_{40}\right) ;$

$a_{3}=\frac{1}{6} k_{30} ; \quad a_{4}=\frac{1}{24} k_{40}$

$\nu=\frac{1}{2 \pi} \frac{M_{02}^{1 / 2}}{M_{20}^{1 / 2}}$

$\lambda(x)=v T \exp \left(-\frac{x^{2}}{2}\right)$

Note that Eqs. 25 and 26 are similar to the expressions which have been obtained for the linear case, but that $\nu$ let the moments $M_{02}$ and $M_{20}$, which result from the nonlinear calculation. On the other hand, the Eq. 22 exhibits a correction factor with respect to the linear calculation: by using the fact that $(\log \lambda)(\log \nu T)^{-1}$ is small with regard to 1 , in a similar way to the linear case, the Eq. 26 may be written:

$x=\sqrt{2 \log v} T\left(1-\frac{\log \lambda}{2 \log v T}\right)$.

Eqs. 13, 22, 23 and 27 lead to:

$F_{\max }(\xi)=\exp \left\{-\lambda\left(1+\phi_{1}-\phi_{2} \log \lambda\right)\right\}$ 
in which

$\phi_{1}=\sum_{j=0}^{4} a_{j}\left(\sqrt{2 \log \nu T)^{j}} ; \quad \phi_{3}=\sum_{j=1}^{4} j a_{j}\left(\sqrt{2 \log \nu T)^{j}} ;\right.\right.$

$\phi_{2}=\frac{\phi_{3}}{\left(\sqrt{2 \log \nu T)^{2}}\right.}$

By taking into account Eqs. 23, 27 and 28, the mean value of the positive extreme values over $T$ given by Eq. 14 is now written:

$\bar{d}_{\max }=M_{20}^{1 / 2}\left\{\left(1+\phi_{1}-\phi_{2}\right) \sqrt{2 \log \nu T} I N-\frac{1}{\sqrt{2 \log \nu T}}\left(1+\phi_{1}-\phi_{2}\right.\right.$

$\left.\left.+\phi_{3}\right) J N+\frac{\phi_{2}}{\sqrt{2 \log v T}} K N\right\} \ldots \ldots \ldots \ldots \ldots \ldots \ldots \ldots \ldots \ldots \ldots \ldots \ldots \ldots$

in which $\left.I N=\int_{0}^{b} \exp \left\{-\lambda\left(1+\phi_{1}-\phi_{2} \log \lambda\right)\right\} d \lambda\right]$

$J N=\int_{0}^{b}(\log \lambda) \exp \left\{-\lambda\left(1+\phi_{1}-\phi_{2} \log \lambda\right)\right\} d \lambda$

$K N=\int_{0}^{b}(\log \lambda)^{2} \exp \left\{-\lambda\left(1+\phi_{1}-\phi_{2} \log \lambda\right)\right\} d \lambda$

and where the upper bound $b$ is a large positive number such that:

$\exp \left\{-b\left(1+\phi_{1}-\phi_{2} \log b\right)\right\} \leq \epsilon$

in which $\epsilon$ being a very small positive number (note thar in the linear case $b=\nu T)$. The Eqs. 31 leads to the following relationships:

$\left(1+\phi_{1}-\phi_{2}\right) I N=1+\phi_{2} J N$

$\left.\left(1+\phi_{1}-\phi_{2}\right) J N=-\gamma-\log \left(1+\phi_{1}\right)+\phi_{2} K N+\phi_{2} L N\right\}$.

in which $\gamma=0.577$ is Euler's constant and

$L N=\int_{0}^{b}\left(\int_{\lambda\left(1+\phi_{1}\right)}^{+\infty} t^{-1} e^{-t} d t\right)(1+\log \lambda) e^{\phi_{2^{\lambda} \log \lambda}} d \lambda \ldots \ldots \ldots$

By replacing Eq. 33 in Eq. 30, the following expression is obtained:

$\bar{d}_{\max }=M_{20}^{1 / 2}\left[\sqrt{2 \log v T}+\frac{\gamma+\log \left(1+\phi_{1}\right)}{\sqrt{2 \log \nu T}}-\frac{\phi_{2} L N}{\sqrt{2 \log \nu T}}\right] \ldots \ldots$

On the other hand, it is shown (28) that:

$\left|\frac{\phi_{2} L N}{\sqrt{2 \log v T}}\right|<\operatorname{Res}$

in which 


$$
\begin{aligned}
& \operatorname{Res}=\frac{\left|\phi_{3}\right|}{(\sqrt{2} \log \nu T)^{3}}\left\{\frac{1}{\left(1+\phi_{1}\right)^{2}} \exp \left[-\frac{\left(1+\phi_{1}\right)}{e}\right]\right. \\
& \left.+2\left[\frac{\log 2}{e\left(1+\phi_{1}\right)}\right]^{1 / 2}\right\} \exp \left[-\frac{\phi_{3}}{2 e \log v T}\right] \ldots \ldots \ldots \ldots \ldots
\end{aligned}
$$

and $e=\exp (1)$. Numerical calculations show that the preceding term is negligible with respect to the others. As a consequence, Eq. 35 can be written as follows:

$\bar{d}_{\max }=g M_{20}^{1 / 2} ; \quad g=\sqrt{2 \log \nu T}+\frac{\gamma+\log \left(1+\phi_{1}\right)}{\sqrt{2 \log \nu T}} \ldots \ldots \ldots$

It is seen that the gust loading factor which has thus been found differs from the linear case by $(2 \log v T)^{-1 / 2} \log \left(1+\phi_{1}\right)$, where $\phi_{1}$ depends on $a_{j}(2 \log v T)^{j / 2}$ for $j \in(0,4)$, and where the $a_{j}$ and $v$ values are functions of the moments $M_{20}, M_{02}, M_{12}, M_{30}, M_{40}, M_{04}, M_{22}$ which have been obtained by a nonlinear calculation. Expressions for the quantities $M_{p q}$ are given in Appendix I.

\section{Numerical Applications}

The writer has developed a computer program that permits the calculation of $f_{2}$, the various $M_{i j}$ moments and $g$. The functions that have been used for describing $U$ and $V$ are given in the Appendix II. Concerning the present example, many numerical tests have been sarried out to check the convergence of the calculated quantities.

This example is a parametric study of the influence of nonlinearity in the presence of resonant amplification effects. The structure has deliberately been chosen as a simple one, and represents a water tower with an area normal to the alongwind direction of $20 \mathrm{~m}^{2}$ (Fig. 1). The drag coefficient is assumed to be $c_{D}=1$. The parametric study consists of varying the following parameters: the height $h_{a}$ of the tower, the fundamental frequency $n_{D}$ of the first bending mode, the rate $\xi_{D}$ of the critical damping of this mode, the average reference velocity $U_{R}$ as well as the terrain roughness whose characteristics are the parameter $\alpha$ of the power law of the mean wind velocity, and the standard deviation of the fluctuation of $V$ at the reference level, $\sigma_{V 10}$. The parameter values of the seven cases which have been studied are summarized in the Table 1 ; all the results are given in S.I. units.

The $d(t)$ observation under study represents the horizontal displacement of the point $m_{s}$ at the top of the cantilever beam. We have taken $T=3,600$ sec. Considering that the surface $S$ is sufficiently small, it has been assumed $n_{s}=1$. For each of the seven cases under study, numerical tests have been carried out in order to determine the values of $T_{1}$ and $n_{T_{1}}$, the results of which are summarized in the Table 2.

Table 2 contains the following data: (1) The moments $M_{p q}$ as defined by Eq. 15 and calculated by Eq. 44 ; (2) the cumulants $k_{p q}$ are calculated by Eq. 20 ; (3) the value $a_{i}$ is calculated by Eq. 24 ; (4) the value $\sigma=M_{20}^{1 / 2}$; (5) the value $\sigma_{L}$ is calculated by using linear theory; (6) the values $\phi_{1}$ and $\phi_{2}$ are calculated by Eq. 29 ; (7) the value $g$ the gust factor is calculated by Eq. 37; (8) the value $g_{L}$, the gust factor is calculated by using linear theory, which 
is such that $g_{L}=\sqrt{2 \log v_{L} T}+0.577\left(2 \log \nu_{L} T\right)^{-1 / 2} ;(9)$ Res, the constant is calculated by Eq. 36; and (8) the values $\epsilon_{\sigma}, \epsilon_{j}, \epsilon_{g}$, and $\epsilon_{g \sigma}$, the relative errors in percentage arising between the results obtained with the linear theory and the present nonlinear theory and pertaining respectively to the standard deviation of the observation process, the standard deviation of its derived process,

TABLE 1.-Parameter Values

\begin{tabular}{|c|c|c|c|c|c|c|c|c|}
\hline $\begin{array}{c}\text { Cas }^{\circ} \\
\text { (1) }\end{array}$ & $\begin{array}{c}1 \\
(2) \\
\end{array}$ & $\begin{array}{c}2 \\
(3) \\
\end{array}$ & $\begin{array}{c}3 \\
(4) \\
\end{array}$ & $\begin{array}{c}\text { Case }^{b} \\
(5)\end{array}$ & $\begin{array}{c}4 \\
(6) \\
\end{array}$ & $\begin{array}{c}5 \\
\text { (7) }\end{array}$ & $\begin{array}{c}6 \\
(8)\end{array}$ & $\begin{array}{c}7 \\
\text { (9) }\end{array}$ \\
\hline $\begin{array}{l}U_{10}(m / s) \\
\sigma_{V_{10}}(m / s)\end{array}$ & $\begin{array}{c}28 . \\
4.6\end{array}$ & $\begin{array}{c}13 . \\
5.8\end{array}$ & $\begin{array}{c}13 . \\
5.8\end{array}$ & $\begin{array}{l}U_{10}(\mathrm{~m} / \mathrm{s}) \\
\sigma_{V_{10}}(\mathrm{~m} / \mathrm{s})\end{array}$ & $\begin{array}{l}28 . \\
4.6\end{array}$ & $\begin{array}{l}28 . \\
4.6\end{array}$ & $\begin{array}{c}13 . \\
5.8\end{array}$ & $\begin{array}{c}13 . \\
5.8\end{array}$ \\
\hline$I_{20}=\sigma_{v_{20}} / U_{20}$ & 0.148 & 0.350 & 0.350 & $I_{80}=\sigma_{\nu_{80}} / U_{80}$ & 0.120 & 0.120 & 0.215 & 0.215 \\
\hline$\alpha$ & 0.15 & 0.35 & 0.35 & $\alpha$ & 0.15 & 0.15 & 0.35 & 0.35 \\
\hline$\xi_{D}$ & 0.05 & 0.03 & 0.05 & $\xi_{D}$ & 0.03 & 0.05 & 0.03 & 0.05 \\
\hline
\end{tabular}

${ }^{\mathrm{a}} h_{a}=20 . \mathrm{m} ; S=20 \mathrm{~m}^{2} ; c_{D}=1 . ;$ constant stiffness $=85300 . \mathrm{N} / \mathrm{m} ;$ concentrated mass at the point $m_{S}=2161$. $\mathrm{kg}$; and $n_{D}=1 . \mathrm{Hz}$.

${ }^{\mathrm{b}} h_{a}=80 . \mathrm{m} ; S=20 \mathrm{~m}^{2} ; c_{D}=1 . ;$ constant stiffness $=85300 . \mathrm{N} / \mathrm{m}$; concentrated mass at the point $m_{S}=13500 . \mathrm{kg}$; and $n_{D}=0.4 \mathrm{~Hz}$.

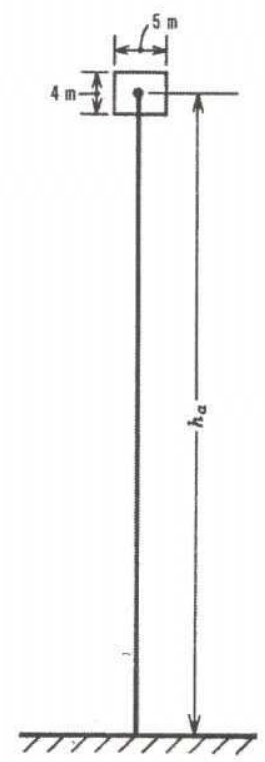

FIG. 1.-Geometry of Water Tower

the $\nu$, the gust factor $g$, and $\bar{d}_{\max }=g \sigma$ over the ovservation time $T=3,600$ sec.

An examination of Table 2 allows to draw the following conclusions:

1. The error in the calculation of $g$ tends to increase as (a) $n_{D}$ increases 


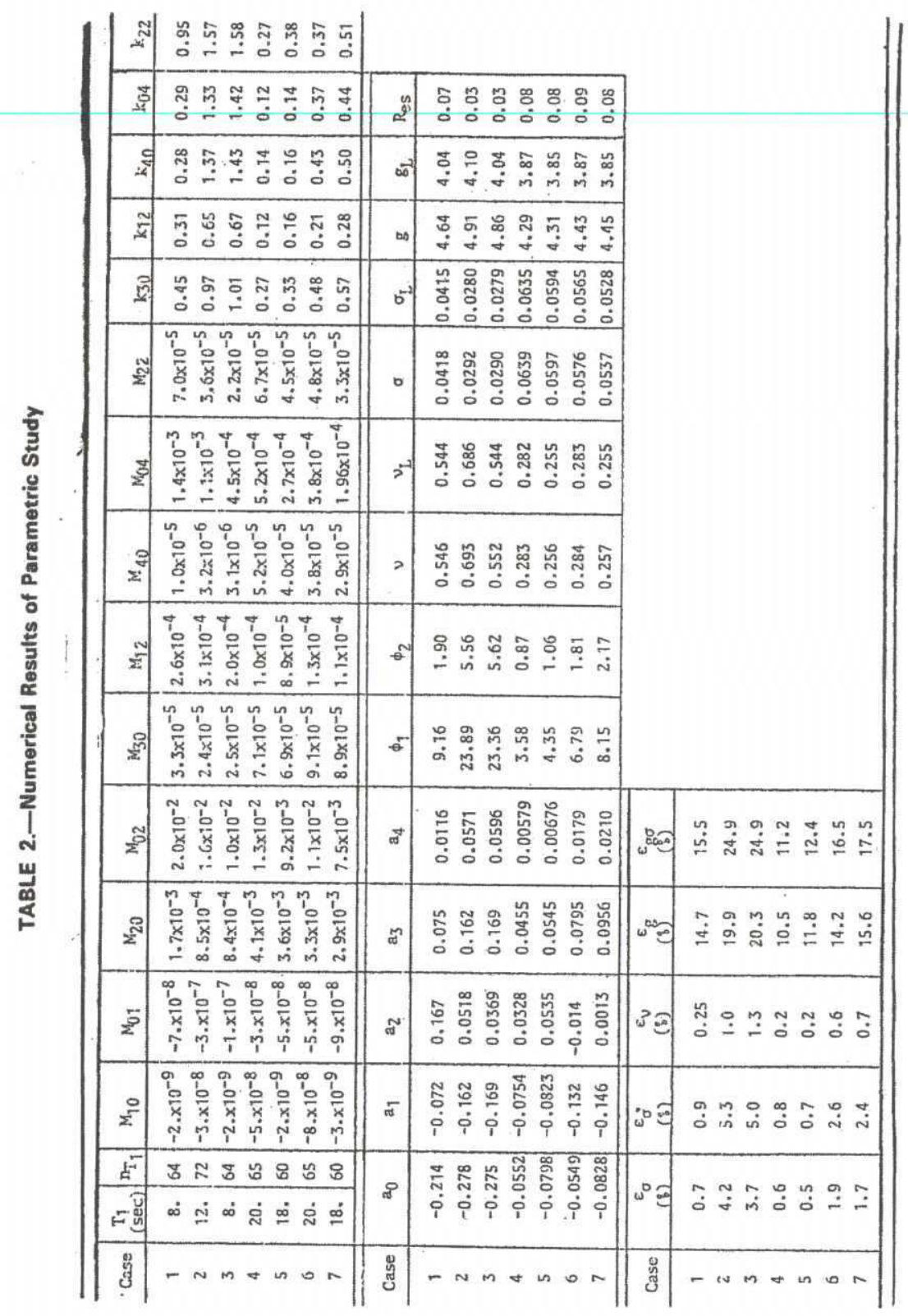


or the height, $h_{a}$, decreases; and (b) the terrain roughness increases. The dependence of this error upon damping is seen to be quite weak.

2. The comparison between the cases 1 and 6 for instance shows that $\epsilon_{g}$ is of the same order in the two cases even though the respective turbulence intensities differ significantly. As a consequence, $\epsilon_{\mathrm{g}}$ would have to be greater for the case 6 than for Case 1. This means that $\epsilon_{\mathrm{g}}$ tends to increase as $n_{D}$ increases.

\section{Conclusions}

An investigation has been presented into the effects of the nonlinear pressure terms, which are neglected in current procedures for calculating alongwind response, upon the magnitude of that response. The analytical procedure used in the investigation has been briefly summarized. The numerical example presented shows that for structures in the range of approx $40 \mathrm{~m}-100 \mathrm{~m}$ height, the errors in the calculation of the fluctuating part of the response is of the order of $10 \%-25 \%$ if the nonlinear terms are ignored. These errors tend to decrease as the terrain roughness decreases, and as the height of the structure increases. The influence of the nonlinear terms is thus particularly significant for structures with heights of the order of $50 \mathrm{~m}$ in urban terrain, subjected to moderate winds such as occur during full-scale response measurements. The results obtained suggest therefore that in interpreting measurements of wind-induced response and, in particular, measurements of wind-induced accelerations, the effect of the nonlinear pressure terms should be taken into account.

\section{Acknowleogments}

The work presented in this paper is based on theoretical research on the quadratic transform of Gaussian processes conducted by P. Kree of the University out at he summary of the results of an investigation carried out at the CTICM (Puteaux-France) within the framework of a research project
on the effects on wind on steel structure.

\section{Appendix I.-Fourier Transform of $f_{2}$}

Generally, only the fundamental vibration mode will be taken into consideration, however higher modes can also be assumed without any additional difficulty. Let $h_{1}(t)$ be the impulse response of the fundamental mode and $\Phi^{\prime}$ the column matrix $(n \times 1)$ of the associated normal mode.

In the last part of this appendix, the indices $i, j, p, q$, will be taken into consideration as an index change such that the index $p$ should correspond to any couple $(i, j)$ of indices and the index $k$ to any couple $(p, q)$ of indices.

Every previously defined $S_{j}$ is partitioned in $n_{j}$ parts. Let be $s_{i j}$ one of the $n_{j}$ parts of $S_{j}$, centered at the point $m_{i j}=m_{\rho}$ and $n_{S}$ the total number of $s_{i j}$
parts of $S$. We have: $S=U_{j} S_{j}=\bigcup_{j} \bigcup_{i=1}^{n_{j}} s_{i j}=\bigcup_{p=1}^{n_{S}} s_{p}$

The time interval $\left[0, T_{1}\right]$ is partitioned in $n_{T_{1}}$ intervals of $\Delta t$ lengths of which
the $q$ th has the origin $t_{q}$. 
The $k$ index associated with $(p, q)$ varies from one to $n_{k}=n_{S} \times n_{T_{1}}$. The polar coordinates $(r, \theta)$ are used. Therefore $\hat{f}_{2}(u, v)=\hat{f}_{2}(r \cos \theta, r \sin \theta)$ which for simplifying purposes will be noted as $\hat{f}_{2}(r, \theta)$. The following quantities have to be defined:

1. The covariance matrix $\mathbf{C}$ of $\left(n_{K} \times n_{K}\right)$ dimension of the stochastic field $V(m, t)$ is such that: $C_{k k^{\prime}}=\mathscr{E}\left\{V\left(m_{p}, t_{q}\right) V\left(m_{p^{\prime}}, t_{q^{\prime}}\right)\right\}=R_{V}\left(m_{p}, m_{p^{\prime}}, t_{q}-t_{q^{\prime}}\right)$ in which $\mathscr{E}$ indicates the mathematical expectation and $R_{V}\left(m, m^{\prime}, \tau\right)$ the crosscorrelation function of the gaussian, stationary $V(m, t)$ process, with zero mean. The $\mathbf{C}$ matrix is symmetric, real, defined and positive. The Chowlesky's decomposition allows to write $\mathbf{C}=\mathbf{L ~} \mathbf{L}^{T}$ with $\mathbf{L}$ being a real, triangular $\left(n_{K}\right.$ $\times n_{K}$ ) matrix.

2. The scalars $w_{K}$ and $\dot{w}_{k}$ are such that:

$w_{k}=\frac{1}{2} \rho_{a}(\Delta t)\left(\sum_{l=1}^{n} Q_{l} \Phi_{l}^{1}\right) \Phi_{p}^{1} h_{1}\left(T_{1}-t_{q}\right) c_{D}\left(m_{p}\right) s_{p} \ldots \ldots \ldots \ldots$

in which $\Phi_{p}^{1}=\Phi_{j}^{1} ; \dot{w}_{k}$ is obtained by replacing $h_{1}$ by $h_{1}$ in the expression of $w_{k}$.

3. The column matrices $\mathbf{A}, \mathbf{B}, \mathbf{E}(\theta), \mathbf{D}(\theta)$ of $\left(n_{K} \times 1\right)$ dimension, as well as the square matrices $\mathbf{W}, \dot{\mathrm{W}}, \mathrm{N}\left({ }^{\theta}\right)$ of $\left(n_{K} \times n_{K}\right)$ dimension are such that:

$A_{k}=2 U\left(m_{p}\right) ; \quad B_{k}=-\sigma_{V}^{2}\left(m_{p}\right) ; \quad W_{k k^{\prime}}=\delta_{k k^{\prime}} w_{k} ; \quad \dot{W}_{k k^{\prime}}=\delta_{k k^{\prime}} \dot{w}_{k} ;$

$\mathscr{E}(\theta)_{k}=(\cos \theta) w_{k}+(\sin \theta) \dot{w}_{k} ; \quad \mathbf{D}(\theta)=\mathbf{L}^{T}\left(\cos \theta \mathbf{W}+\sin \theta \dot{\mathbf{W}}^{\prime}\right) \mathbf{A} ;$

$\mathbf{N}(\theta)=2 \mathbf{L}^{T}(\cos \theta \mathbf{W}+\sin \theta \dot{\mathbf{W}}) \mathbf{L}$

in which $\delta_{l k k^{\prime}}$ is the Kronecker symbol.

The Fourier transform $\hat{f}_{2}$ is then written for any $r \in(0,+\infty), \theta \in(0,2 \pi)$

$\hat{f}_{2}(r, \theta)=\{\operatorname{det}[\mathbf{I}+i r \mathbf{N}(\theta)]\}^{-1 / 2} \exp \left\{-i r \mathbf{E}^{T}(\theta) \mathbf{B}\right.$

$\left.-\frac{1}{2} r^{2} \mathbf{D}^{T}(\theta)[\mathbf{I}+i r \mathbf{N}(\theta)]^{-1} \mathbf{D}(\theta)\right\}$

in which $i$ indicates the pure imaginary complex number, and where $I$ is the unit matrix of $\left(n_{K} \times n_{K}\right)$ dimension (see Ref. 28).

The $N(\theta)$ matrix is a real symmetrical matrix. An orthogonal matrix $\Psi(\theta)$ exists therefore such that $\boldsymbol{\Psi}^{T}(\theta) \Psi(\theta)=\boldsymbol{\Psi}(\theta) \boldsymbol{\Psi}^{T}(\theta)=\mathbf{I}$ and $\boldsymbol{\Psi}^{T}(\theta) \mathbf{N}(\theta) \Psi(\theta)$ $=\boldsymbol{\Omega}(\theta)$, where $\boldsymbol{\Omega}(\theta)$ is a diagonal matrix whose diagonal elements, noted $\boldsymbol{\Omega}_{k}(\theta)$, are the eigenvalues of $\mathrm{N}(\theta)$. We define as follows:

$$
\begin{aligned}
& \beta_{1}(r, \theta)=-\frac{1}{2} \sum_{k=1}^{n_{k}} \operatorname{Arctg}\left(r \mathbf{\Omega}_{k}(\theta)\right)-r \mathbf{E}^{T}(\theta) \mathbf{B} \\
& +\frac{1}{2} r^{3} \mathbf{D}^{T}(\theta) \Psi(\theta)\left[\mathbf{I}+r^{2} \Omega^{2}(\theta)\right]^{-1} \Psi^{T}(\theta) \mathrm{N}(\theta) \mathbf{D}(\theta) \\
& \beta_{2}(r, \theta)=\prod_{k=1}^{n_{k}}\left(1+r^{2} \Omega_{k}^{2}(\theta)\right)^{-1 / 4}
\end{aligned}
$$


$\beta_{3}(r, \theta)=+\frac{1}{2} r^{2} \mathbf{D}^{r}(\theta) \Psi(\theta)\left[\mathbf{I}+r^{2} \Omega^{2}(\theta)\right]^{-1} \Psi^{T}(\theta) \mathbf{D}(\theta)$

and as a consequence $f_{2}$ is defined by the following expression: (see Ref. 28)

$f_{2}(x, y)=\frac{2}{(2 \pi)^{2}} \int_{0}^{+\infty} \int_{0}^{\pi} r \beta_{2}(r, \theta) \cos \left[\beta_{1}(r, \theta)\right.$

$+r(x \cos \theta+y \sin \theta)] \exp \left[-\beta_{3}(r, \theta)\right] d r d \theta$

\section{Calculation of $M_{p q}$ Moments}

It is possible to proceed to an analytical calculation of $M_{20}$ (Ref. 25), but the calculation of the other moments soon becomes extremely difficult. We shall therefore use the Fourier transform $\hat{f}_{2}$ which can be written in polar
coordinate:

$\hat{f}_{2}(r, \theta)=\int_{-\infty}^{+\infty} \int e^{-i r(x \cos \theta+y \sin \theta)} f_{2}(x, y) d x d y$

By successive derivations of Eq. 43 and by proceeding from expression Eq. 40 , it may be shown that:

$M_{10}=q(0) ; \quad M_{01}=q\left(\frac{\pi}{2}\right) ; \quad M_{20}=\mathrm{X}_{1}(0) ; \quad M_{02}=\mathrm{X}_{1}\left(\frac{\pi}{2}\right) ; \quad M_{30}=\mathrm{X}_{2}(0) ;$

$M_{40}=\mathrm{X}_{3}(0) ; \quad M_{04}=\mathrm{X}_{3}\left(\frac{\pi}{2}\right) ; \quad M_{12}=-\frac{1}{3} M_{30}+\frac{\sqrt{2}}{3}\left(\mathrm{X}_{2}\left(\frac{\pi}{4}\right)\right.$

$\left.-\mathrm{X}_{2}\left(\frac{3 \pi}{4}\right)\right) ; \quad M_{22}=\frac{1}{3}\left(\mathrm{X}_{3}\left(\frac{\pi}{4}\right)+\mathrm{X}_{3}\left(\frac{3 \pi}{4}\right)\right)-\frac{1}{6}\left(M_{40}+M_{04}\right)$

in which: $\quad \mathrm{X}_{1}(\theta)=q^{2}(\theta)+z(\theta) ; \quad \mathrm{X}_{2}(\theta)=q^{3}(\theta)+3 q(\theta) z(\theta)+3 s(\theta) ;$ $\mathrm{X}_{3}(\theta)=q^{4}(\theta)+6 q^{2}(\theta) z(\theta)+12 q(\theta) s(\theta)+3 z^{2}(\theta)+12 t(\theta)$ and:

$q(\theta)=\frac{1}{2} \operatorname{Tr}[\Omega(\theta)]+\mathbf{E}^{T}(\theta) \mathbf{B} ; \quad z(\theta)=\mathbf{D}^{T}(\theta) \mathbf{D}(\theta)+\frac{1}{2} \operatorname{Tr}\left[\mathbf{\Omega}^{2}(\theta)\right] ;$

$s(\theta)=\mathbf{D}^{T}(\theta) \mathbf{N}(\theta) \mathbf{D}(\theta)+\frac{1}{3} \operatorname{Tr}\left[\mathbf{\Omega}^{3}(\theta)\right] ;$

$t(\theta)=\mathbf{D}^{T}(\theta) \mathbf{N}^{2}(\theta) \mathrm{D}(\theta)+\frac{1}{4} \operatorname{Tr}\left[\mathbf{\Omega}^{4}(\theta)\right]$

where $\operatorname{Tr}[\cdot]$ designates the trace of the matrix $[\cdot]$. The accuracy of the numerical calculations of the moments $M_{y}$ with regard to some possible analytical calculations depends on: (1) The width of $\left(0, T_{1}\right)$; and (2) the partition fineness of the $S_{j}$ and of $\left(0, T_{1}\right)$, i.e., values of $n_{S}$ and $n_{T_{1}}$.

To estimate the obtained accuracy, one must check that $1 / 2 \operatorname{Tr}[\Omega(0)]+$ 
$\mathbf{E}^{T}(0) \mathbf{B}$ and $1 / 2 \operatorname{Tr}[\boldsymbol{\Omega}(\pi / 2)]+\mathbf{E}^{T}(\pi / 2) \mathbf{B}$ are near to zero and that $\mathbf{D}^{T}(0)$ $\mathbf{D}(0)$ is near to the variance of linearly calculated variance $d(t)$. Then, the calculated $M_{i j}$ moments are near to the actual values which could possibly have been obtained by an analytical calculation.

\section{Appendix II}

Hermite Polynomials. - The hermite polynomials are $H_{0}(x)=1 ; H_{3}(x)=x^{3}$ $-3 x ; H_{1}\left(x\left(=x ; H_{4}(x)=x^{4}-6 x^{2}+3 ;\right.\right.$ and $H_{2}(x)=x^{2}-1$.

Wind Functions used in Numerical Calculations - It is the writers intention to adopt simple assumptions of functions which describe the wind structure in order to simplify the numerical calculations. This should not change the type of results $U(m)=\bigcup_{10}(z / 10)^{\alpha}$ in which $z=$ the height of the point $m$ expressed in meters

$\sigma_{V}(m)=\sigma_{v: 0}=$ constant

By taking into account the small dimension of the windward surface in the

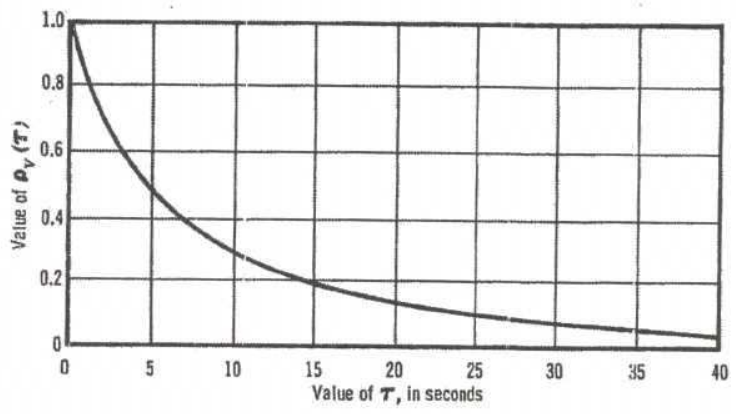

FIG. 2.--Correlation Function of $V$

numerical example as well as a simplifying measure, it has been put:

$R_{V}\left(m, m^{\prime}, \tau\right)=\sigma_{V 10}^{2} \rho_{V}(\tau)$

where $\rho_{V}(\tau)$ is the function defined by Fig. 2 .

\section{Appendix III.-References}

1. Biétry, J., Sacre, C., and Sirniu, E., "Mean Wind Profiles and Charge of Terrain Roughness," ISO/TC98/SC3/WG2, Paper for European ISO Committee, Berlin, Germany, 1976.

2. Chen, P. W., et al., "Response of Triangular Prisms in Turbulent Wind," Journal of the Structural Division, ASCE, Vol. 97, No. ST11, Proc. Paper 8526, Nov., 1971, pp. 2679-2690.

3. Cramer, H., The Elements of Probability Theory and Some of its Applications, John Wiley and Sons, Inc., New York, N.Y., 1955.

4. Cramer, H., and Leadbetter, M. R., Stationary and Related Stochastic Processes, John Wiley and Sons, Inc., New York, N.Y., 1967.

5. Davenport, A. G., "The Dependence of Wind Loads on Meteorological Parameter," Internaticnal Research, Ottawa, Canada, 1967, pp. 20-34. 
6. Davenport, A. G., "Note on the Distribution of the Largest Value of a Random Function with Application to Gust Loading," Proceedings of the Institution of Civil Engineers, Vol. 28, June, 1964, pp. 187-196.

7. Davenport, A. G., "Gust Loading Factors," Journal of the Structural Division, ASCE, Vol. 93, No. ST3, Proc. Paper 5255, June, 1967, pp. 11-34.

8. Davenport, A. G., "The Spectrum of Horizontal Gustiness near the Ground in High Winds," Quarterly Journal, Vol. 87, London, England, 1961, pp. 194-211.

9. Davenport, A. G., "The Application of Statistical Concepts to the Wind Loading of Structures," Proceedings of the Institution of Civil Engineers, Vol. 19, Aug., 1961, pp. 449-472.

10. Duchêne-Marullaz, P., "Structure du vent en zone sub-urbain-Rugosité et corrélation latérale," EN.CLI, 76-2, Cahiers du Centre Scientifique et Technique du Batiment, Nantes, France, June, 1976.

11. Harris, R. I., "The Nature of the Wind," Paper 3 in the Construction Industry Research and Information Association Seminar on the Modern Design of Wind-Sensitive Structures, Institution of Civil Engineers, London, England, June, 1970, pp. 29-55.

12. Hino, M., "Spectrum of Gusty Wind," Part I, International Wind Conference, Tokyo, Japan, 1971.

13. Hino, M., "On the Gust Factor-Relationship between the Instantaneous Maxima and Averaging and Sampling Times," Proceedings of the Fourteenth Japan National Congress for Applied Mechanics, 1961.

14. Krasnopolsky, M., "Calcul des Efforts dus à une Haoule Aléatoire sur les Structures," Thèse de Docteur-Ingénieur, Université de Paris VI, 1975.

15. Krée, P., "Equations aux Dérivées Partielles en Dimension Intinite," Séminaire lère année, Institut Henri Poincare, Paris, France, 1975.

16. Leadbetter, M. R., “On Crossings of Levels and Curves by a Wide Class of Stochastic Processes," Annales of Math. Stat., Vol. 37, 1966.

17. O'Rourke, M. J., et al., "Response of Structures to Random Wind Forces," Journal of the Structural Division, ASCE, Vol. 101, No. ST12, Proc. Paper 11786, Dec., 1975, pp. 2557-2571

18. Peterka, J. A., and Cermak, J. E., "Wind Pressures on Buildings-Probability Densities," Journal of the Structural Division, ASCE, Vol. 101, No. ST6, Proc. Paper 11373, June, 1975, pp. 1255-1267.

19. Rice, S. O., "Mathematical Analysis of Random Noise," Bell System Technical Journal, Vol. 18, 1944, Vol. 19, 1945.

20. Saul, E., and Peyrot, A. H., "Response to Stochastic Wind of $N$-Degree Tall Buildings," Journal of the Structural Division, ASCE, Vol. 102, No. ST5, Proc. Paper 12112, May, 1976, pp. 1059-1075.

21. Shiotani, M., and Iwatani, Y., "Correlation of Wind Velocities in Relation to the Gust Loading," Proceedings of the Third Conference on Wind Effects on Buildings and Structures, Tokyo, Japan, 1971, pp. 57-68.

22. Simiu, E., "Gust Factors and Along-Wind Pressure Correlations," Journal of the Structural Division, ASCE, Vol. 100, No. ST4, Proc. Paper 9686, Apr., 1973, pp. 773-783.

23. Simiu, E., "Equivalent Static Wind Loads for Tall Building Design," Journal of the Structural Division, ASCE, Vol. 102, No. ST4, Proc. Paper 12057, Apr., 1976, pp. 719-737

24. Simiu, E., and Lozier, D. N., "The Buffeting of Tall Structures by Strong Winds," Building Science Series 74, Center for Building Technology, National Bureau of Standards, Washington, D.C., Oct., 1975.

25. Simiu, E., and Vaicaitis, R., "Nonlinear Pressure Terms and Along-Wind Response," Journal of the Structural Division, ASCE, Vol. 103, No. ST4, Proc. Paper 12837, Apr., 1977, pp. 903-906.

26. Soize, C., "Transformation Quadratique d'un Processus Gaussien et Application à la Dynamique Stochastique," Journal de Mécanique, Paris, Firance, Vol. 15, No. 5, 1976, pp. 857-875.

27. Soize, C., "Calcul des Structures à Barres Soumises au vent Aléatoire," Construction Métallique, Centre Technique Industriel de la Construction Méallique, No. 1, Putequz, France, 1977.

28. Soize, C., "Dynamique Stochastique des Structures Soumises au vent Aléatoire en 
Tenant Compte des Termes Nori-Linéaires de la Fluctuation Depression," Rapport Centre T'echnique Industriel de la Construction Méallique, No. 80050-2, Putequz, France, 1977.

29. Solnes, J., and Sigbjörnsson, R., "Along-Wind Response of Large Bluff Buildings," Journal of the Structural Division, ASCE, Vol. 99, No. ST3, Proc. Paper 9585, Mar., 1973, pp. 381-398.

30. Vaicaitis, R., et al., "Parametric Study on Wind Loading on Structures," Journal of the Structural Division, ASCE, Vol. 99, No. ST3, Proc. Paper 9634, Mar., 1973, pp. $453-468$.

31. Vellozi, J., and Cohen, E., "Gust Response Factors," Journal of the Structural Division, ASCE, Vol. 94, No. ST6, Proc. Paper 5980, June, 1968, pp. 1295-1313.

32. Vickery, B. J., and Kao, K. H., "Wrag or Along-Wind Response of Slender Structures," Journal of the Structural Division, ASCE, Vol. 98, No. ST1, Proc. Paper 3635, Jan., 1972, pp. 21-36.

33. Vickery, B. J., "Wind Action on Simple Yielding Structures," Journal of the Engineering Mechanics Division, ASCE, Vol. 96, No. EM2, Proc. Paper 7204, Apr., 1970, pp. 107-120.

34. Vickery, B. J., and Davenport, A. G., "A Comparison of Theoretical and Experimental Determination of the Response of Elastic Structures to Turbulent Flow," Proceedings of the Second Conference on Wind Effects on Buildings and Structures, Ottawa, Canada, Vol. 1, 1967, pp. 705-738. 